\title{
Identification and Visual Rhetoric in Modern Advertisement Theory
}

\author{
Abdullah S. Darwish, PhD. Candidate \\ PhD Composition \& TESOL Program, College of Humanities \& Social Sciences/Indiana University of Pennsylvania, USA \\ E-mail: a.s.darwish@iup.edu/abdullah.sleman@yahoo.com
}

\section{Doi:10.5901/ajis.2015.v4n3p11}

\section{Abstract}

In this paper, I have tried to develop an analytical framework to account for the value and important use of visual rhetoric in modern advertisement theory through adopting Burke's (1969) notion of identification. I have shown how identification in advertisements with visual images is created by such strategies as naming, framing, symbol use, perfection principle, negativity principle and social hierarchy notion. Initially, identification needs some visual deviation to establish its existence. This suggested analytical framework of identification here has been integrated with modern advertisement theory framework which has three main variables: attracting attention, arousing pleasure, and making the message long-lasting in the minds of the audience. Through applying these two frameworks, I attempt to show how modern advertisers mold their advertisements not only to persuade the target audience but also to create identification which leads to a long term consumerism relationship between the advertised product/service and the target audience. In all cases, a minimum degree of pre-established knowledge on the side of the audience is required to work out the covert relationship between the visual images and the advertised product/service in order to achieve identification and its consequential long term consumerism relationship.

Keywords: Visual Rhetoric/Deviation, Identification, Naming, Framing, Symbol Use.

\section{Introduction}

Research on visual rhetoric has been expanding in an attempt to account for the different visual representations in today's world especially in modern advertisements. Although some research has been done to address the relationship between visual rhetoric and modern advertisement theory, there is still a gap in this field. Visual rhetoric research has been either put under the umbrella of verbal rhetoric or has not established its own independent interpretative framework. For example, Mulken $(2003,2006)$ sheds light on the relationship between visual and verbal rhetoric in advertisement on the basis of the interpretive verbal framework of McQuarrie \& Mick (1996, 1999, 2003). Enschot, Hoeken, and Mulken (2008) try to explore the complexity levels between verbo-pictorial tropes and schemes. Another study by Mazoughi and Abdelhak (2011) focuses on "[testing] the impact of stylistic elements in advertising that form visual and verbal rhetorical figures on imagery and recall" (p. 257). Köksal's (2013) study explores how visual elements lead to persuasion without working out any analytical framework that can be used in later analyses.

All the aforementioned studies focus on the use of and the relationship between visual and verbal rhetoric to create persuasion without working out an established framework of analysis. Besides, they address persuasion through visual rhetoric without attending to the long term relationship of consumerism that modern advertisement theory attempts to establish. Thus, my objective in this paper is to develop and expand a more interpretive analytical framework that explicitly accounts for the value and use of visual rhetoric in modern advertisements. In order to do develop the aforementioned framework, I will adopt Burke's (1969) notion of identification which has been originally used in analyzing verbal rhetoric. In verbal rhetoric/advertisement formula, identification refers to the association between the advertised product/service and the advertisement target audience through naming, framing, symbol use, perfection and negativity principles, and social hierarchy (Christopher, 2013). Besides, identification has another dimension related to the very basics of modern advertisement theory which are: attracting attention, arousing pleasure, and creating recallable links between the visual elements together in an advertisement on the one hand, and between that advertisement and the audience on the other hand. Henceforth, I will show how modern advertisement theory not only uses identification to create persuasion but also to create a long term consumerism relationship between the advertised product/service and the target audience. This relationship is perpetuated in the psychological/social bondage between the advertisement and the audience that exceeds persuasion.

In order to establish the scene for exploring this consumerism relationship, I would echo Burke's (1966) definition of rhetoric as "all symbolic forms used by people in their attempt to influence others" (as cited in Grancea, 2014, p. 147). 
This definition of rhetoric as an umbrella term to any symbolic use to influence the thoughts and feelings of people is very essential because it helps interpret the creation of identification between the visual elements in an advertisement and the target audience to create a long-term consumerism relationship. Because identification is a very comprehensive and complicated process, this definition of rhetoric makes it possible to show how this identification is created within a broader rhetorical theory.

\section{Visual Rhetoric and Visual Deviation}

Visual rhetoric and visual deviation are two important tools used by modern advertisers that need to be addressed. Bulmer \& Oliver (2006) describe visual rhetoric "as a form of communication that uses images for creating meaning or constructing an argument. [They add], an analysis of visual rhetoric considers how images work alone and collaborate with other elements to create an argument designed for moving a specific audience" (as cited in Köksal, 2013, p. 80). The use of visual rhetoric is potentially maintained to create visual deviation. I will rhetorically use the term visual deviation to refer to what McQuarrie \& Mick (1996) call artful deviation. This deviation "occurs when an expression deviates from expectation, the expression is not rejected as nonsensical or faulty [but rather contextualized in one way or another]" (McQuarrie \& Mick, 1996, p. 425). For example, the use of metaphor leads to deviation as in he is a lion which is not rejected as nonsensical but rather meaningfully recontextualized. The sentence is cognitively re-interpreted as: He is as brave as a lion. The same process of deviation happens with the use of visual elements in advertisement which leads to influencing the target audience and creating a longer term consumerism through identification. The use of a visual image of a celebrity with a certain product, so to speak, leads to visual deviation because there is no direct relationship between that image and the product advertised. Yet, the visual deviation is not rejected as nonsensical but rather recontextualized by the audience as meaningful. The following figures help explain the notion of visual deviation:

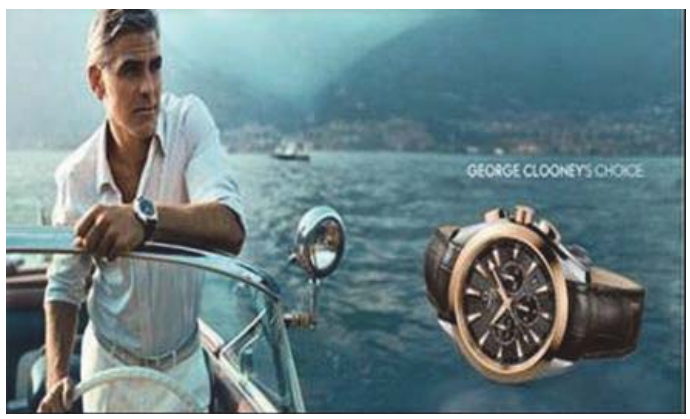

Figure 1. Omega watch Ad with George Clooney.

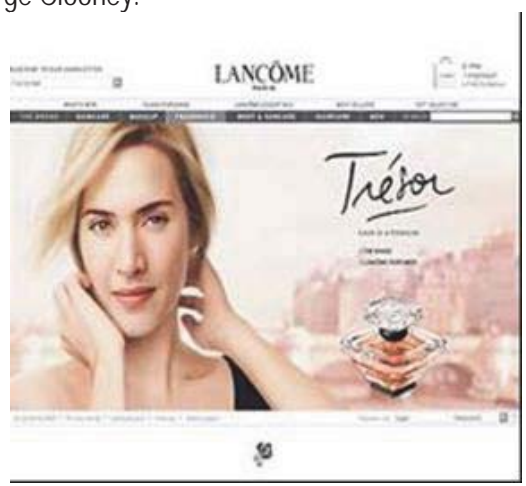

Figure 2. Kate Winslet - Tresor Perfume.

In these advertisements, there is a form of visual deviation. In the first advertisement, Omega watch is advertised by 
attaching the product to the image of the famous American actor and producer George Clooney. The visual deviation here is created due to the lack of direct relationship between the product and the image of the famous American actor. This lack of direct relationship is not interpreted as nonsensical but rather the target audience is stimulated to create a covert link between the product and the image of the famous actor; that is, his being a loyal consumer of the product advertised. The same is repeated with the Tresor Perfume advertisement by attaching the image of Kate Winslet, the famous British actress which is associated with visual deviation too. This relationship will be further explained in the analysis section.

\section{Modern Advertisement Theory and Visual Rhetoric}

Modern advertisement theory (MAT) has worked to provide advertisers with all the tools that make them survive and thrive in an environment of heavy competition. Through using visual elements, MTA aims not only to persuade the target audience but also to establish strong consumerist relationships through identification. In fact, MAT works within three multifaceted and interconnected levels which are recursive by nature. It starts with attracting one's attention, then it moves toward creating a halo of liking/arousing pleasure, and finally it tries to create memorable links between the consumer and the advertised product/service (McQuarrie \& Mick, 1996, 427) as in the following figure:

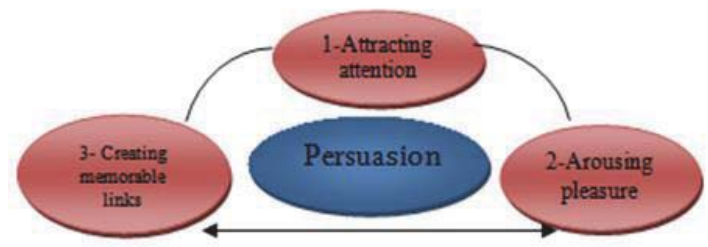

Figure 3. A model of the dynamics of the modern advertisement theory

In the figure above, it can be noticed that advertising has three interconnected links. These links are recursive and dependent on the dynamics of rhetoric. Not only do they interact to create persuasion but also to establish a long term consumerism. Attracting attention is the first stage in having the target audience react to the visual elements used in an advertisement. The second stage is that of arousing pleasure through the visual deviation initiated by the use of the visual elements. Finally, this deviation creates a long-lasting link between the advertisement and the audience. On one level, these stages interact with one another to build a bond between the advertisement and the audience. On another level, they integrate with the visual elements to create identification and a long-term consumerism with the audience through the way the visual elements are presented. From a rhetorical perspective, any proposition can be expressed in a variety of ways and that in any given situation one of these ways will be the most effective in swaying an audience. Hence, when persuasion is the overriding goal, the rhetorical perspective suggests that the manner in which a statement is expressed may be more important than its propositional content. (McQuarrie \& Mick, 1996, 424)

Thus, the use of visual elements is not effective by itself but by the way these elements are framed and presented. In other words, the way these elements are matched and presented should potentially lead to a form of identification and thus long term consumerism. Through their visual deviations, visual images are consciously or unconsciously contextualized by the audience and lead to a form of identification (Christopher, 2013, 774). A visual image starts with attracting the attention of the targeted audience, then creates a form of visual arousal and finally ends up with long-lasting effect of being recalled, persuasive, and self-identified. Its visual elements attract attention, and while trying to account for a relationship between the ad and the visual elements, the interpreter's processing of this deviation makes him/her experience what is called by Berlyne (1971) a pleasurable degree of arousal (as cited in McQuarrie \& Mick, 1996, p. 427). This "pleasure of processing [...] influences the appreciation of the ad, and this might enhance its persuasive force. [That is, c]onsumers will have a favorable attitude towards the product, service, or idea, because the processing of the ad is experienced as joyful" (Mulken, 2003, p. 115).

Visual deviation potentially leads to the audience's likelihood to recall the message for a longer time. This likelihood of long-lasting message recall by the audience due to visual deviation is supported by two sub-elements. The first one is that the matching of the visual figures in an unexpected way presents a pleasant message to the audience so that they can remember it longer; the second is that this unexpectedness necessitates effortful processing on the side of 
the audience and thus becomes cognitively long-lasting (McQuarrie \& Mick, 1996, p. 433).

Another important point to be mentioned here is that visual rhetoric/deviation requires pre-established knowledge in the mind of the target audience that helps recontextualize covert connections between the visual image and its visual deviation and the essence of the advertisement (Köksal, 2013, p. 84). The lack of any pre-established cues could lead to incompetency in interpreting the visual message and its visual deviation (Grancea, 2014). For example, using the Mona Lisa in an advertisement about airlines requires a pre-established knowledge of what is the Mona Lisa. As a painting, it stands for originality and innovation. A viewer who ignores what this painting stands for may fail to work out the visual deviation in the advertisement and thus fails to work out a form of identification between the two elements in the advertisement on the one hand, and between him and the advertised product on the other hand. Accordingly, the notion of visual deviation serves the three micro-functions that modern advertisement theory utilizes, namely: attracting attention, arousing pleasure and being memorable to serve the macro-function of creating identification and long consumerism.

\section{Visual Deviation and Identification}

Advertisements target consumers through not only persuading them but also building an emotional link between the product and the consumer. That is, although we have many different roles in life and have many moral standings, all "these and other characteristics appear to recede in importance as secondary qualities of a basic aspect of modern lifeconsumption" (Sack, 1988, p. 642). Thus, advertisers have realized that working in a world of consumerism and competitiveness necessitates the use of highly molded messages that penetrate into the minds and emotions of the audience and create that bond of interconnection. These bonds are associated with the use of visual figures and lead to identification between the advertisement and the target audience. The concept of identification is mainly based on Burke's work and means a "process of acting-together". Those who share identification have sensations, attitudes, etc. in common while being unique from each other at the same time (Burke, 1969, pp. 20-21).

The role of audience has been thoroughly discussed in rhetorical theory by Aristotle, Cicero, and other classical rhetoricians. Aristotle argues that one of the most influential modes of persuasion is through "putting the audience into a certain frame of mind. [That is,] persuasion may come through the hearers, when the speech stirs their emotions". He adds: "Our judgments when we are pleased and friendly are not the same as when we are pained and hostile" (Aristotle, p. 7). Cicero emphasizes that in order to persuade, we need to attend to the mental emotions of the audiences (along with other requirements). These "mental emotions [... should be] intimately understood, because it is in calming or kindling the feelings of the audience that the full power and science of [rhetoric] are to be brought into play" (Cicero, p. 291). Henceforth, identification building between the audience and the visual figures has been heavily utilized by modern advertisers not only to persuade the audience but also to create longer consumerism.

In order to build the desired identification, advertisers usually depend on three strategies: symbol use, naming and framing. Within visual rhetoric context, symbol use potentially refers to using certain visual image. It is associated with three sub-strategies: the negativity concept, hierarchy/social structure, and perfection. Negativity is associated with creating an identification that glorifies the positive qualities in the visual figure and the advertisement on the one hand; and the qualities of the visual figure and the audience on the other hand through implicit calls for identification. Hierarchy or social structure is associated with using symbols in a way that makes the audience believe that a person is climbing the ladder of social status from lower to higher. Perfection is associated with using visual figures that makes the audience strive to belong to the elite (Christopher, 2013).

Naming is the second strategy that is used to build bonds with the audience. Within a verbal rhetorical context, naming is created through the use of proper names, demonstratives, etc. to maintain a friendly identification with the audience. But within a visual rhetorical context, it is created through using an image of an established figure that is recognizable by the audience as being special or unique in a way or another. Finally, framing refers to how advertisers mold their visual messages and advertisements to make the audience see the world from a different perspective (Christopher, 2013). In the following section I will apply these strategies to analyze how visual figures in two ads lead to identification and long consumerism.

\section{Methodology}

In order to develop and apply the framework of identification to account for the value and underpinnings of visual rhetoric in modern advertisements, two modern advertisements with visual rhetorical elements are chosen and the identification 
framework is applied to them. In the first level, I will show how visual deviation attracts attention, arouses pleasure, and creates memorable links between the advertisement elements and the target audience as well as initiating a micro form of identification. In the second level, I will show how identification creation through strategies of naming, symbol use, perfection, social hierarchy, and negativity leads not only to persuasion but also long-term relationship of consumerism.

\subsection{Analysis of the way identification is created through visual elements}

In what follows, I will first show how the elements of attracting attention, arousing pleasure and creating memorable links are created through visual rhetoric and what relationship it has with identification. Then in the second level, I will show how concepts of naming, framing, symbol use, perfection, social hierarchy, and negativity are used to account for identification and its effect on the audience.

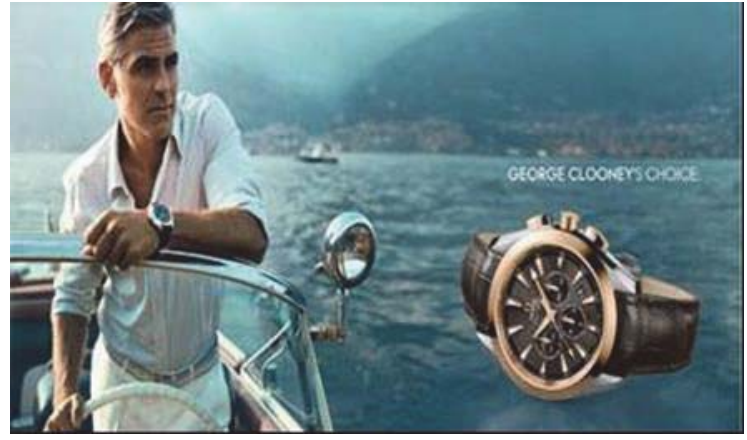

Figure 1. Omega watch Ad with George Clooney.

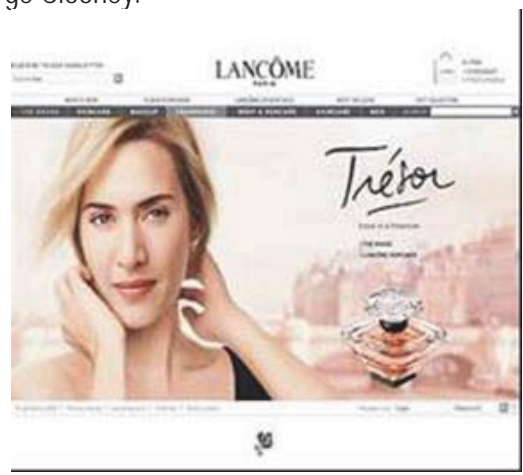

Figure 2. Kate Winslet - Tresor Perfume.

In Figure.1, we see an Omega watch advertisement with the image of George Clooney (an American actor, writer and producer). Here, there is a visual deviation component represented by the lack of overt relationship between Omega watch and the image of Clooney. This deviation attracts the attention of audience who will try to make connection between the two visual elements. As the audience does so, it experiences some kind of pleasure on the basis of what Berlyne (1971) calls a pleasurable degree of arousal of processing to establish a link between the two unrelated elements (as cited in McQuarrie \& Mick, 1996, p. 427). Since the audience will not invalidate that there is no relationship between Omega watch and Clooney's image, on the contrary it will create a recallable link between them based on that audience's pre-established knowledge. The relationship between Omega watch and Clooney's image will be interpreted in terms of an identification between them as the latter is a loyal consumer of Omega watch and what social implications this all has as it will be explained below.

Since the first level of identification has been established, the second and more macro level comes into the fore. 
Omega is a world famous watch brand produced by Omega SA Company with long-established history of watch-making which is located in Switzerland. George Clooney is a famous American, award-winning actor and producer. The advertiser wants to create a form of positive identification between the two and thus calls the audience to have identification with the product as prestigious, elite-exclusive and chic by portraying it being worn by highly prestigious and special people like George Clooney. Starting with naming, the advertiser creates a connection between the product and the celebrity as establishing two famous and prestigious entities, framing the two as not only exclusive but also unique, and the two visual elements in the advertisement are symbolically matched. This match leads to creating another form of perfection on the side of those who wear Omega watches as belonging to the club of elitism and high social status with no negative side. That is, celebrities are usually depicted as special in their accomplishments, physique, emotions...etc. and less associated with negativities. Although there is no absolute perfection and they might lead difficult lives, they are usually presented through media as special and of higher social status. Through simply matching the two visual elements in the advertisement, there are implicit calls for the audience to look for such an identification with the product to attain the qualities associated with this identification.

The second advertisement in figure 2 brings together the image of Tresor Perfume from Lancôme Paris, the French luxury perfumes and cosmetics house, and the image of Kate Winslet, the famous British actress. As with the first advertisement, the visual deviation component is initiated due to the absence of explicit connection between Tresor Perfume and Kate Winslet which attracts the audience's attention. Thus, the audience will try to process the covert relationship between the two and ends with pleasurable processing experience and working out an easily recallable link between the two visual elements in the advertisement. Again, this leads the audience to attend to the first level of identification between Tresor Perfume and Winslet. Consequently, the second level of identification is triggered off. This macro type of identification is created with consideration to the fame of Winslet as an established and global awardwinning actress as well as Lancôme Paris's fame for being a well-known company for first-class cosmetics and perfumes. The advertiser wants to convey that both of Winslet and Tresor Perfume are to be identified with having high qualities of elegance, femininity, beauty, attraction, etc. and have been identified with each other. The same strategies we have noticed in the advertisement of figure 1, the strategies of naming, framing, etc. are also used in this advertisement. Kate Winslet's and Lancôme Tresor's names add to each other, are framed in a way of exclusive prestige through the symbolic use of visual images. They are associated with perfection, higher social status and attractiveness. Thus, this incorporates a call for the audience to buy this perfume to have access into and identification with this club of elitism and exclusiveness.

Accordingly, the use of visual images has a strong effect on creating bonds of identification which lead to long consumerism. It makes the audience consider "that by consuming prestigious products they enhance their self-esteem, communicate themselves to others as people who are socially desirable, and gain a membership in respected clubs" (Köksal, 2013, p. 82).

\section{Conclusion}

In this paper, I have tried to develop an analytical framework to account for the value and use of visual rhetoric in modern advertisements through adopting Burke's (1969) notion of identification. Through applying identification along with visual deviation, I have re-addressed the relationship between visual rhetoric and modern advertisement. At the first level, visual deviation has been used to show how modern advertisement theory framework maintains its very direct initial goals: attracting attention, arousing pleasure, and creating recallable links and the consequential initial micro identification which leads to a more macro one. The second level of identification (macro one) is of higher importance in modern advertisement theory because it is associated with not only creating persuasion but also a long term relationship of consumerism. This macro identification is initiated by such supportive strategies of naming, framing, symbol use, negativity/perfection principles and social status. Although it has been potentially used within the context of verbal rhetoric, I have applied this framework -with its identification as well as visual deviation components- to account for the dynamism of visual rhetoric in modern advertisements. In order to present a more comprehensive picture, the application of this analytical framework here has been integrated with that of the modern advertisement theory. Accordingly, this integration has shown how modern advertisers try to create a longer consumerism relationship which requires more than a simple persuasion of the value of the product/service advertised but maintaining identification with it instead.

In order to understand and work out identification and visual deviation, a pre-established knowledge on the side of the target audience is required. The lack of pre-established knowledge could lead to incompetent interpretation of the covert connection between the visual image and the advertised product/service on the one hand, and that visual image 
and its loaded identification and the target audience on the other hand. Through analyzing two visual advertisement excerpts, I hope I managed to show how identification is used to establish a long consumerism relationship. Finally, I would argue that Burke's (1969) framework of identification (and that of visual deviation) will provide more theoretically and practically solid stance for researchers to explore relationships of consumerism pertinent in modern visual advertisements. More research needs to be done to show how long consumerism and identification interact and are utilized by modern advertisers.

\section{References}

Aristotle, Rhetoric. Trans. W. R. Roberts (2004). New York: Dover Publications, Inc.

Burke, K. (1969). A rhetoric of motives. New York: Prentice-Hall, INC.

Christopher, A. A. (2013). Rhetorical strategies in advertising: The rise and fall pattern. Academic Journal of Interdisciplinary Studies, 2 (8), 773-781.

Cicero, De Oratore. In Bizzell, P. \& Herzberg, B. (2000). (Eds.). The rhetorical traditions: Reading from the classical times to the present (pp. 289-338). New York: Bedford/St. Martin's.

Enschot, R, Hoeken, H and Mulken, M. (2008). Rhetoric in advertising: Attitudes towards verbo-pictorial rhetorical figures. Information Design Journal 16(1), 35-45.

Grancea, I. (2014). Visual rhetoric and framing strategies in advertising word-based product categories. .Argumentum - Journal of the Seminar of Discursive Logic, Argumentation Theory and Rhetoric, 21(1), 146-162.

Köksal, F. N. (2013). The Role and Usage of Visual Rhetoric in Advertising. Online Journal of Communication and Media Technologies, Special issue, 78-86.

McQuarrie, E. F. \& Mick, D. G. (1996). Figures of rhetoric in advertising language. The Journal of Consumer Research, 22 (4), 424-438.

Mulken, M. V. (2003). Analyzing rhetorical devices in print advertisement. Document Design, 4(2),114-128.

Mulken, M. V. (2006). Towards a new typology for visual and textual rhetoric in print advertisements. European Advances in Consumer Research, 7, 59-65.

Mzoughi, N \& Abdelhak, S. (2011). The Impact of visual and verbal rhetoric in advertising on mental imagery and recall. International Journal of Business and Social Science, 2(9), 257-267.

Sack, R. D. (1988). The consumer's world: Place as context. Annals of the Association of American Geographers, 78(4), 642-664. 
